\title{
ANALYSIS AND ASSESSMENT OF SWEDISH VAULTED MASONRY STRUCTURES USING FUNICULAR METHODS
}

\author{
CARL THELIN $^{1 *}$ AND FOLKE HÖST ${ }^{2}$ \\ ${ }^{1}$ Linnæus University and Tyréns AB \\ Linnæus University, \\ 35195 Växjö, Sweden \\ e-mail: carl.thelin@Inu.se \\ (*corresponding author) \\ ${ }^{2}$ Tyréns AB \\ Tyréns AB, Scheelevägen 17 \\ 22370 Lund, Sweden \\ e-mail: folke.host@tyrens.se
}

Keywords: Historic masonry structure, masonry vaults, thrust line analysis, funicular analysis, thrust network analysis

\begin{abstract}
Practising structural engineers working with historic masonry structures need access to further developed methods to analyse and assess the structural behaviour of masonry vaults. The aim of this study is to evaluate methods to analyse vaulted masonry structures and to develop a methodology for the application of suitable methods to the work of practising structural engineers. A secondary aim is to use the methods studied to analyse and assess the structural behaviour of three Swedish church buildings of different types and with vaulted structures. The churches are Gökhem church, a small parish church built in the 12th century, and the Lund cathedral, also built in the 12th century; both originally in the Romanesque style but with later alterations. The third church is St Johannes church in Stockholm, built in the neogothic style in the late 19th century. The methods used are parametric graphic statics of thrust line analysis and Thrust Network Analysis (TNA), both based on funicular analysis. The results show the strength of using such methods to assess and evaluate the structural behaviour of historic vaulted masonry structures. They provide a pedagogical description of the structural behaviour of masonry vaults and the conditions that affect their load-carrying capacity. Another result is the implementation of a method to perform the analysis in a feasible and effective way. For the analysed church buildings, the results provide an understanding of their structural behaviour and clearly show how different variables affect the magnitude and impact of the thrusting force. Thrust Network Analysis has great potential to become a very effective method to perform advanced $3 d$ analyses of masonry vaults but needs to be developed in order to enable "best fit solutions" to map the thrust network to the shape of the existing vaults. Such methods are under development.
\end{abstract}




\section{INTRODUCTION}

In the work of practising structural engineers, with a focus on historic masonry buildings, the commissions often relate to structural problems, such as cracking, movement and weathering of materials, or to restoration and reconstruction. Frequently, there are arches and vaults in the buildings and questions concerning their structural behaviour and their impact on the surrounding structures are common. Structural engineers working with historic masonry structures need to have access to further developed methods to analyse and assess the structural behaviour of masonry vaults.

The work initiated by Heyman [1], to apply limit analysis to masonry load-bearing structures, in combination with the rapid development in recent decades of computer-based methods to analyse vaulted masonry structures, has provided a frame-work that entails new possibilities for engineers to assess such buildings.

The main aim of this study is to evaluate methods to analyse vaulted masonry structures. During the work it became evident that there was a need to develop a methodology for the application of suitable methods to the work of practising structural engineers. This became a supplementary aim. With further developed methods it is possible to make more efficient and safer assessments of historic masonry structures. The methods studied are based on funicular analyses, since they are considered suitable $[1,2,3]$ for this field of work. The methods used are Thrust Network Analysis [3] and thrust line analysis using parametric graphic statics [4,5]. The methods are examined by using three Swedish church buildings with vaulted structures as case

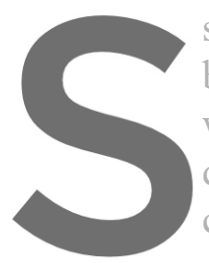
studies. A secondary
behaviour of the obje
work; general researc
questions concerning
case studies.
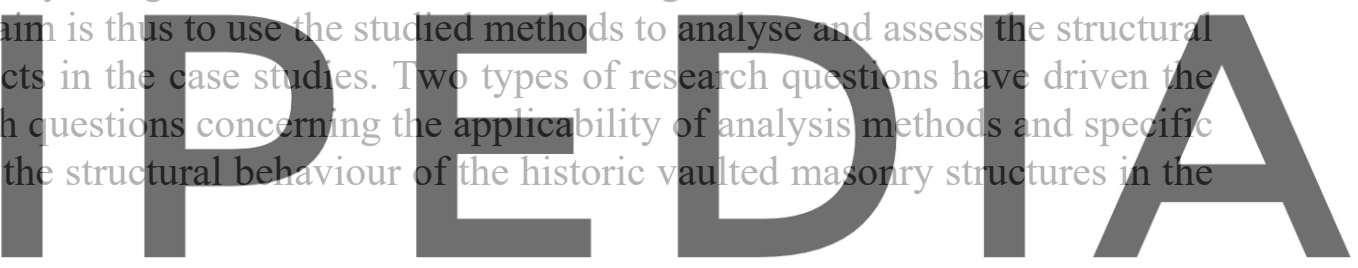

\section{METHOD}

Register for free at https//www.scipedia.com. to download the version without the watermark Since the ain of the study is to investigate methods to analyse historic vaulted masonry structures in engineering practice, three masonry buildings have been used as cases to test and develop methods and ways of working. By using real structures with relevant structural problems that consultant engineers have encountered, it is possible to determine how applicable and adaptable the methods are, and their potential and the need to develop them further. In addition, the case studies provide knowledge of how historic masonry structures carry loads as well as other aspects of decisive importance for their structural behaviour. The objects chosen for the case studies represent three different types of historic masonry structures with vaults.

\subsection{Capture geometry}

In order to analyse the structural behaviour of vaulted masonry structures, a precise description of their geometry is crucial, regardless of the methods used to analyse them. To achieve accurate measures of the vaulted shapes, laser scanning and photo scanning were used $[6,7]$, see Figure 1. The scans need to be carried out on both the intradoses and extradoses of the vaults, and it is also necessary to capture the dimensions of walls, pillars and other relevant geometric information. In many cases, insulation or other obstructing objects on the extradoses of the vaulted structures need to be removed or taken into account in some other way. 

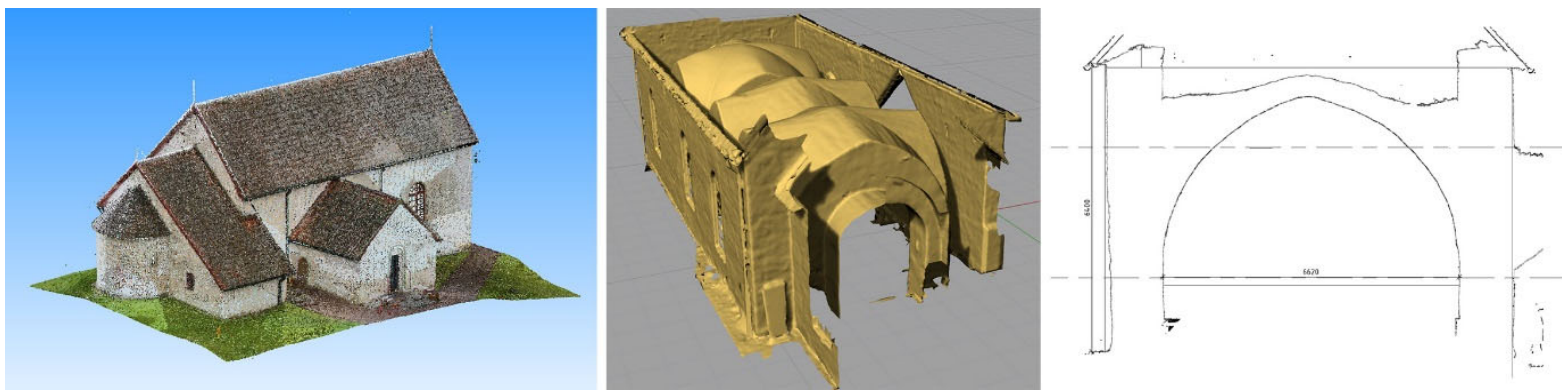

Figure 1: Left: laser-scanned point cloud of the Gökhem church; middle: meshed model of vaults and walls, and right: a section rendered by using the point cloud.

\subsection{Thrust Network Analysis}

Funicular force networks have been introduced [8] as an extension of the thrust line analysis to also include three-dimensional structures, and has been further developed into Thrust Network Analysis, TNA [3,9]. The Block Research Group at ETH Zürich has developed the RhinoVAULT software to carry out Thrust Network Analyses [10,11]. With RhinoVAULT, Thrust Network Analysis can be carried out within the graphic interface of Rhinoceros [12]. This is an advantage, as the $3 \mathrm{~d}$ models of vaulted structures produced from the laser scans can be managed easily and effectively in Rhinoceros.
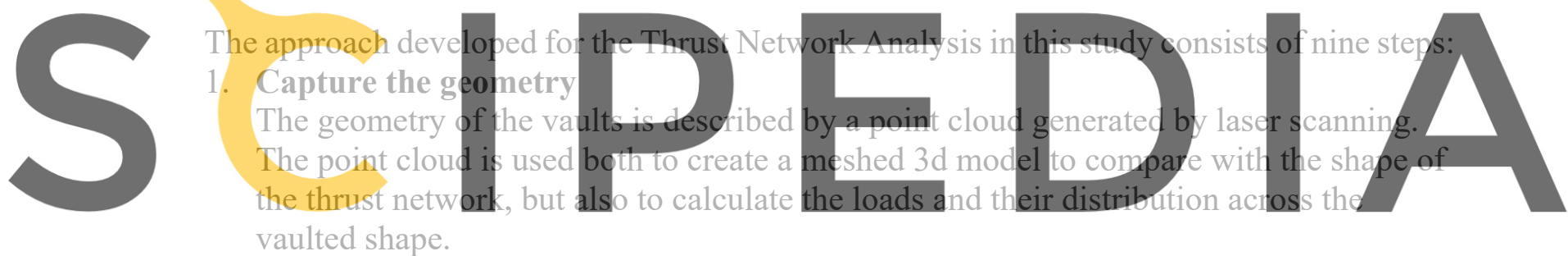

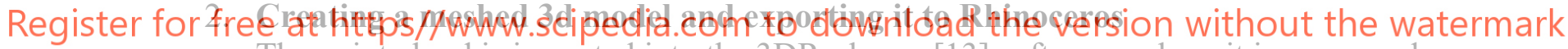
The point cloud is imported into the 3DReshaper [13] software, where it is processed and divided into different parts in different layers to facilitate the analysis; for example, walls, extradoses of vaults and intradoses of vaults. A meshed $3 \mathrm{~d}$ model is created in 3DReshaper, exported and then imported into Rhinoceros.

3. Calculation of loads

The main load usually consists of the weight of the vault, determined by its volume and density. In some cases, heavy filling at the haunches of the vaults can provide a considerable load. In cases where the extradoses of the vaults are more or less covered by insulation or some other material, the volume of the vaults has been calculated on the basis of the area of the intradoses and the thickness of the vaults. The thickness can usually be determined by using the point cloud in combinations with an investigation in situ.

\section{Choice of form diagrams for Thrust Network Analysis}

The Thrust Network Analysis requires the creation of a form diagram. In this project, four different diagrams with different densities have been used. The shape of the vault should guide the choice of the form diagram and it is an advantage if the analyst has an understanding of how the load is carried by the vault. 


\section{Determination of points for support}

Before the height of the thrust network can be calculated, the placing of the support of the thrust network needs to be defined. These points represent locations where the vault is supported by walls or columns. In many cases, there are massive masonry walls and it is not at all obvious at what level and how far within the wall the vault is actually supported. Since the structure is statically indeterminate, it is not possible to know the exact location of the support and extreme possibilities therefore have to be studied to find possible solutions. In this study, a framework with five to seven possible vertical positions in combination with three horizontal positions in a defined grid has been used, see example in Figure 2.

6. Creation of force and thrust networks in RhinoVAULT

The force and thrust networks are created by RhinoVAULT when the supports and form diagrams are given.

7. Distribution of loads across the geometry of the vault

In the Thrust Network Analysis, the total load of the vault and other loads are first given. The load is evenly distributed over the discreet nodes of the thrust network by tributary areas [14] as default. If loads should be positioned in another way, which may

be the case with vaults of varying thickness or filling at the haunches, the load must be manually moved to and from the nodes that should carry more or less load.

8. Fitting of thrust networks relative to vault geometry

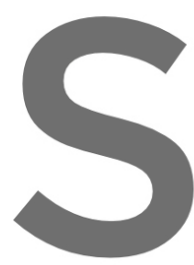

The lack of an automated "best fit" solution to map pos

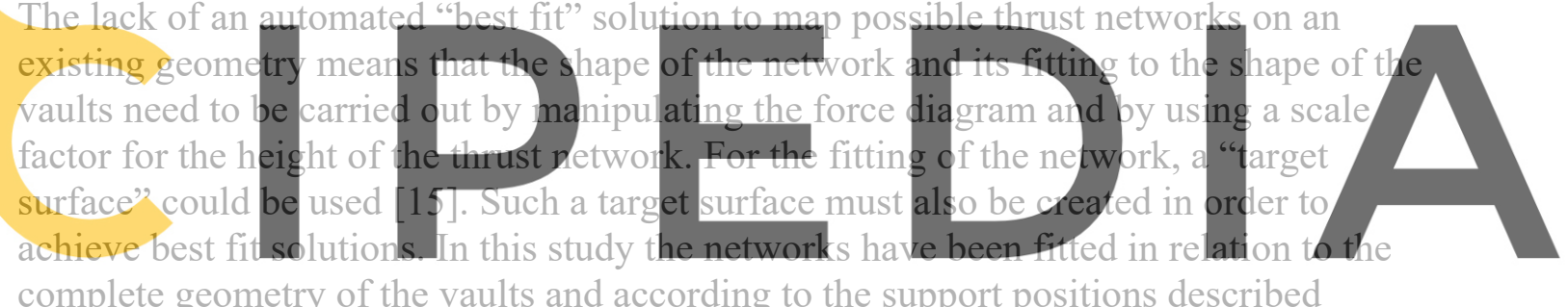

Register for freebat

9. Results of the Thrust Network Analysis

If it is possible to find a solution to the thrust network within the geometry of the vault, the conditions of Heyman [1] are fulfilled and the network presents one possible solution for the structural behaviour of the vault, see example in Figure 2. 

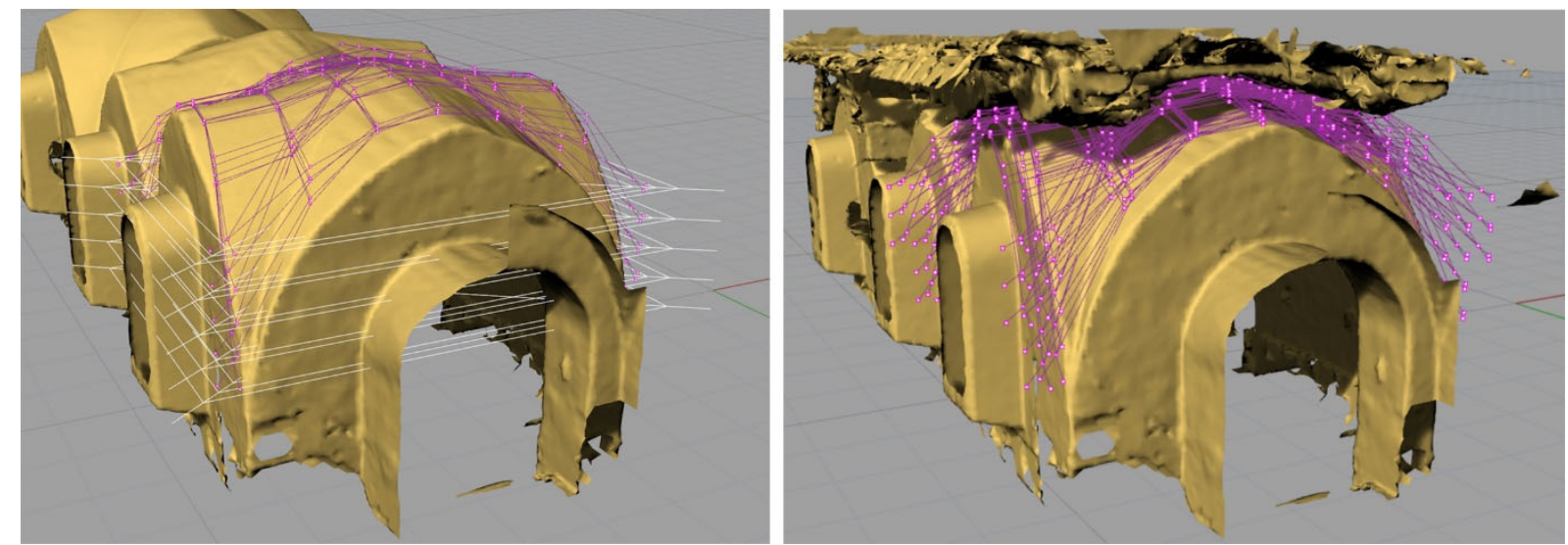

Figure 2: Left: grid for different support positions in the vertical and horizontal direction; right: Possible shapes and positions of thrust networks in a Thrust Network Analysis.

In the available version of RhinoVAULT it is not possible to use "best fit" or "closest fit" solutions for thrust networks on predefined geometries. There are several studies that describe strategies and algorithm to carry out such analyses $[15,16,17,18]$. Without solutions for best fit analyses the possibilities to fit the thrust networks to thin complex vault geometries are limited, and it is also more difficult to generate the most extreme shapes in the networks that yield minimum and maximum horizontal thrust, respectively. On the other hand, the need to fit the shape of the thrust networks manually by improved understanding structure. In some cases, converge into a solution in cases where it is simply not possible to fit a structure.
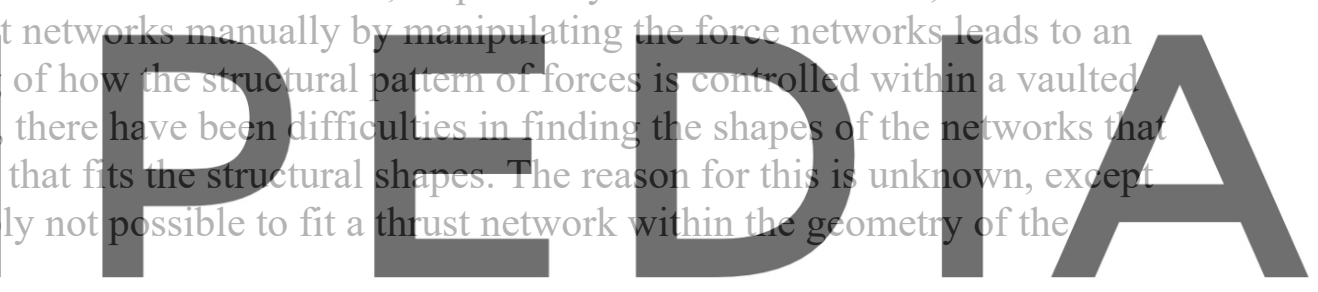

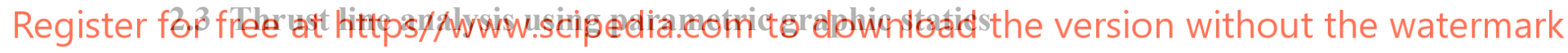

Thrust line analysis using parametric graphic statics has been used and developed previously by the authors $[5,7]$, and has been further developed within this research project. The Geogebra [19] software was used to build the models, see example in Figure 3. The models were used to examine how the thrusting force from the vaults is carried by the building's walls and columns to the foundations by studying appropriate sections where the load from the vaults meets the surrounding structures. Parametric analysis of the vaults using the slicing technique [5] was also carried out in order to compare with the results from the Thrust Network Analysis. 

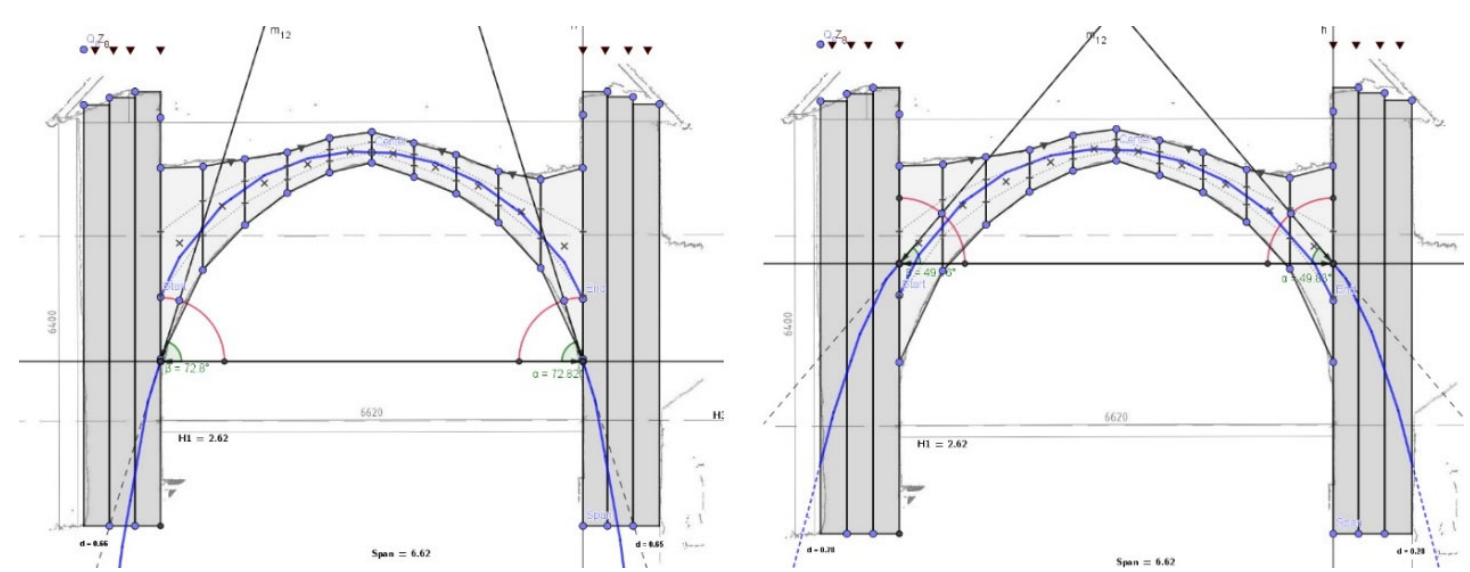

Figure 3: Examples of thrust line analysis using parametric graphic statics.

The approach developed for the parametric thrust line analysis in this study consists of five steps:

1. Preparation of a section of the building for analysis

The section for study is produced from the laser-scanned point cloud using Revit [20]

or corresponding software. The sections are dimensioned at strategic places for scaling

in Geogebra. The sections can be produced from a drawing based on the point cloud or

directly from the point cloud, see example in Figure 1.

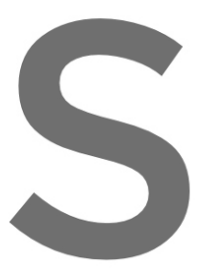

2. Definition of the

In the Geogebra

defined. The dep

of the part of a wall that contributes

Adjustments to re

loads, such as loads from

roof structure,
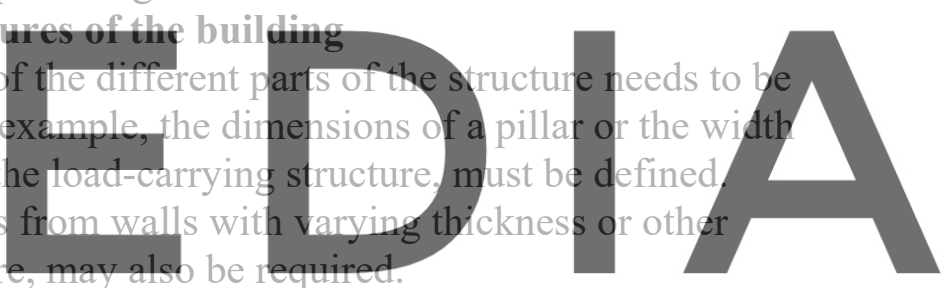

3. Determination of loads

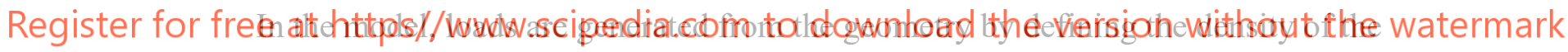
material. Loads from vaults are provided by their magnitude, direction and point of application. Loads from vaults are given by the Thrust Network Analysis or an analysis using the slicing method.

4. Fitting of thrust line relative to the vault geometry

The location of the thrust line within the geometry is manipulated according to the objective of the analysis. Many times, it is desirable to try to fit the thrust line within the middle third of the structure to ensure its safety and minimise the risk of cracking.

5. Comparisons between different load cases

The parametric thrust line analysis enables fast comparisons between different load cases and their impact on the structural behaviour of the building.

The combination of the results from the Thrust Network Analysis of the vaults (or pseudo$3 \mathrm{~d}$ analysis using the slicing method) and the models for parametric thrust line analysis by appropriate sections gives a description of the complete flow of forces in the analysed buildings. The models provide an understanding of the structural behaviour, an assessment of the safety margins of the load-carrying structure and an understanding of how changes in the load or in the structure affect the structural behaviour. 


\section{CASE STUDIES}

The case studies involved three objects: Gökhem church, Lund cathedral and St Johannes church in Stockholm, see Figure 4. The churches represent three different types of structures with masonry vaults and pose different questions concerning their structural behaviour.

Many questions regarding the structural behaviour of the case study objects was analysed in the study. Here, only a few examples of results are presented.
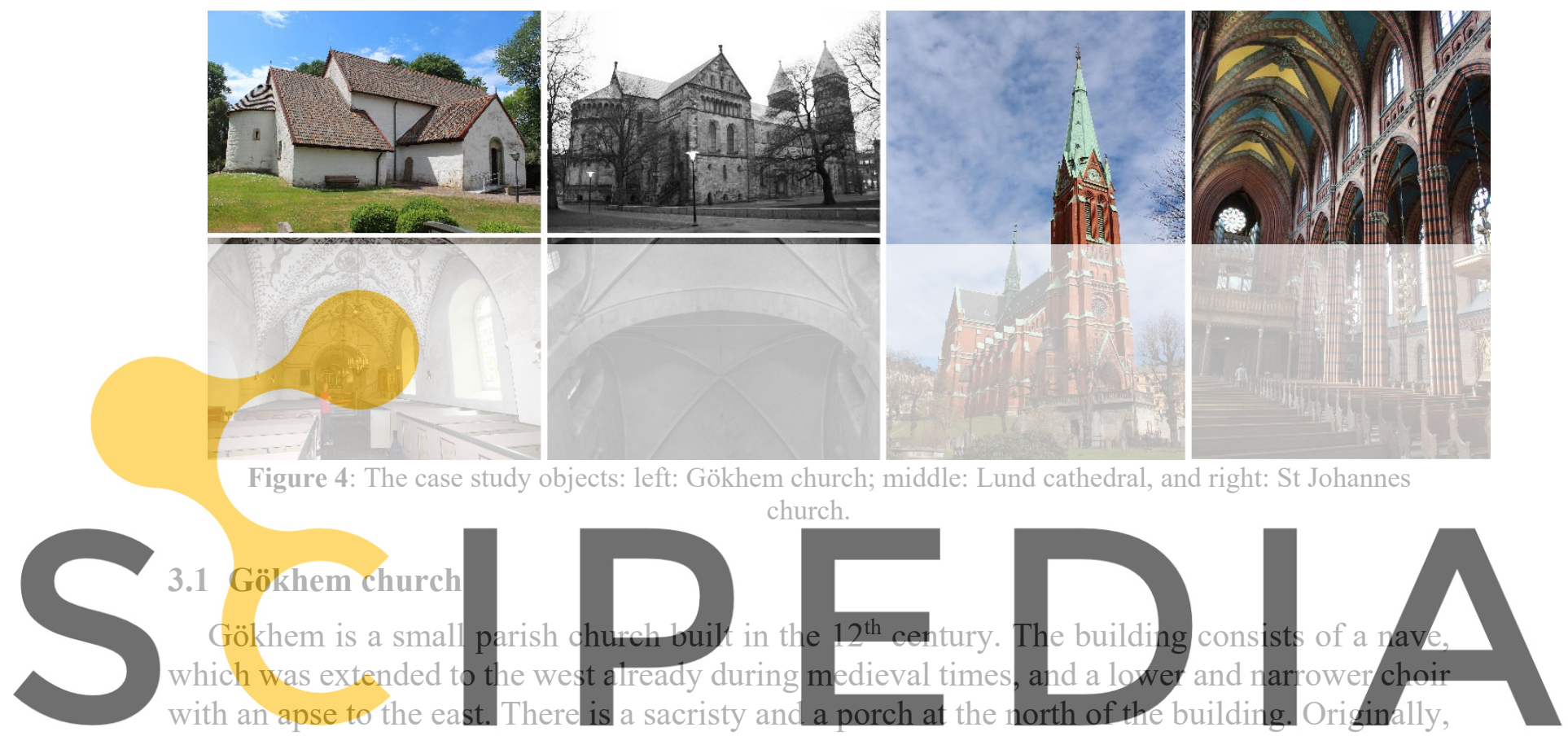

the building did not have vaults but an open roof structure. The vaults are of limestone and were

Register foriffireetlat 15 tht

The building has been the main object for testing of the different methods and comparison

of the results. One specific question was how different factors concerning the shape of the vault and its meeting with the supporting wall affect the structural behaviour, and another how different loading situations from the roof structure affect the structural behaviour.

\subsection{Lund cathedral}

Lund cathedral was first built in the $12^{\text {th }}$ century. The church has three naves, with a transept, a choir and an apse in the Romanesque style. It has been rebuilt and restored several times. The main nave has a total of six rib vaults that were constructed after a fire in 1234 . The side aisles have eight vaults each. Buttresses were added during the $16^{\text {th }}$ century. They were later removed during the $19^{\text {th }}$ century and tie rods were installed in the main nave. In the $19^{\text {th }}$ century restoration, the vaults of the main nave were probably partially rebuilt and changed.

Two questions of interest concerning the Lund cathedral is whether the former buttresses with flying buttresses were necessary to support the thrusting forces of the vaults and, consequently, if the current tie rods are equally necessary. 


\subsection{St Johannes church}

St Johannes church in Stockholm was built between 1884 and1890 in the neo-gothic style. It has three naves and a transept. The choir is located to the north and the tower and main entrance to the south. The church is constructed of brick masonry, with details such as tracery, mouldings and sculptures made of concrete. The church has been restored several times. In the restoration carried out in 1970-1974, the vaults were found to have severe cracks and extensive reinforcement of them was required. Measurements were made of the vault geometry and the cracks and a thrust line analysis was carried out. The results showed two types of damages to the vaults. Firstly, they lack the capacity to carry loads to the supports by the diagonal ribs; instead, the load is directly transferred to the adjacent arches. This has led to cracking along the bricks in the upper part of the vaults. This damage was not considered dangerous and was only repaired and not reinforced. Secondly, there was an imbalance between the lower parts of the vaults since the part of the vault adjacent to the walls was much steeper than the ones next to the crossing arches. This had led to severe cracking of the diagonal ribs and a risk of collapse. Reinforcements were introduced to counteract the imbalance of the structure.

One question of interest for St Johannes church is whether it is possible to validate the structural analysis and the described structural behaviour that were presented during the restoration in the early 1970s. Furthermore, questions concerning the importance of the flying buttresses were studied as well as the way in which the load is carried through the structure from the vaults by way of columns, walls and buttresses.
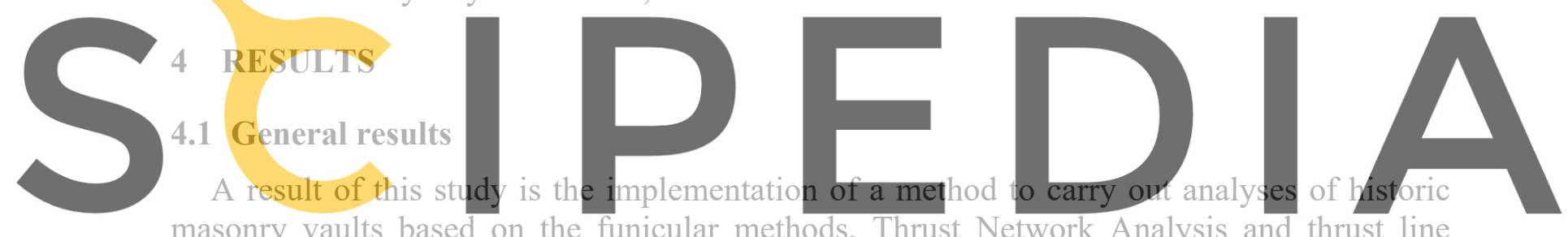

masonry vaults based on the funicular methods, Thrust Network Analysis and thrust line

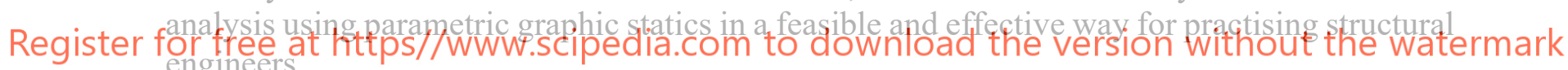

For this study the Thrust Network Analysis has been carried out using the RhinoVAULT software. The main purpose of RhinoVAULT today is to perform form-finding for intuitive creation and exploration of compression-only structures. The program is not adapted to analyse existing structures such as historic masonry vaults. Still, it is possible to carry out analyses of many vaulted structures in the current configuration of the program and many vaults have a shape that make it possible to find several valid solutions within their geometry. The results can also provide information on the structural behaviour, even though it has not been possible to fit thrust networks completely within their geometry. For cases where thrust networks are successfully found within the geometry, it is known from Heyman [1] that the shape of the network represents one possible load path, and this indicate that the vault has a shape that can carry its load by compression only. The results of the Thrust Network Analysis made within this project have thus been the same or more conservative than those obtained by parametric thrust line analysis by means of the slicing method, which was unexpected.

In order to obtain results that are more precise, TNA solutions based on best fit algorithms need to be applied to get a better fit of the thrust networks to predefined geometries. These solutions are not implemented in RhinoVAULT today. 
Still, TNA solutions by means of RhinoVAULTS with the methods and the way of working developed in this project make the analysis of the structural behaviour, thrusting forces and studies of how different conditions affect the results much faster than previously. Furthermore, the use of $3 \mathrm{~d}$ models gives a better understanding of complex vaulted structures.

The models for parametric thrust line analysis make it possible to connect the result of the analysis of the vaults to an analysis of the behaviour of the complete building.

\subsection{Case study: Gökhem church}

For the Gökhem church structural type with thick vaults it is easy to find, thrust networks that fit within the geometry, and consequently, show possible structural behaviours with TNA, see Figure 5. The parametric thrust line analysis using the slicing method gave solutions with lower thrust than could be found with TNA. This is possibly due to not finding networks with a "deep" enough solution, which would probably have been facilitated by a best fit solution.

The analysis of the vaults of Gökhem church gives a range of valid results of thrust networks that fit within the geometry of the vault. To find possible solutions, the structural behaviour of the complete building needs to be considered to be able to disregard results that give thrusting forces of a magnitude and direction that cannot be supported by the walls.

The results show three factors that interact and are decisive to the magnitude of the horizontal thrusting force: the weight and shape of the vault, the angle of the thrusting force at the location where the vault meets the supporting structure, and the height of this location, which is the
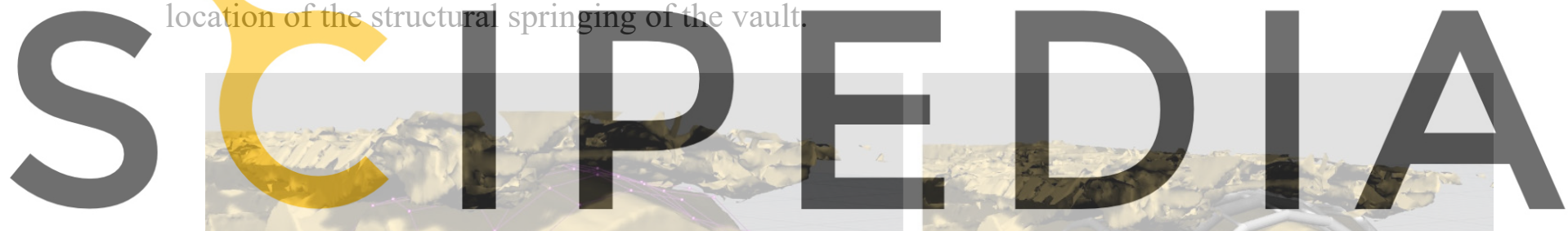

Register for free at https//www.scipedia.com to download the version without the watermark
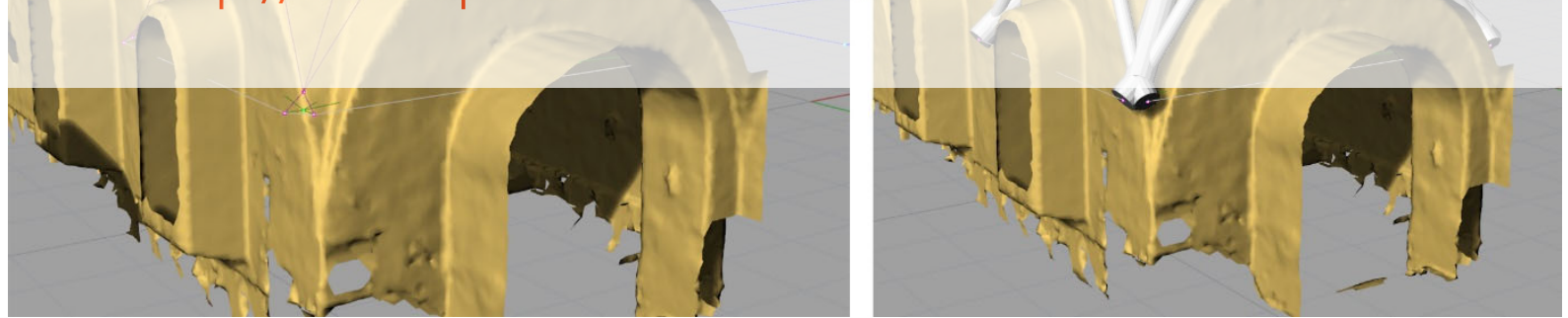

Figure 5: Example of results from thrust network analysis of Gökhem church.

\subsection{Case study: Lund cathedral}

The thin geometry of the vaults in the main nave of Lund cathedral limited the possibilities to find thrust networks with TNA that fitted the geometry, although it was possible with parametric thrust line analysis and the slicing method. Despite this, it was possible to draw conclusions on the magnitude of the thrusting forces that arise from the vault under different conditions. A comparison between an "almost fit" of a TNA network and parametric thrust line analysis shows good conformity with respect to supporting forces.

The analysis of a section shows that the former buttresses probably had a significant task to 
support the thrusting forces from the vaults of the main nave. The tie rods that replaced them in the $19^{\text {th }}$ century are thus important for the structural safety of the building.

\subsection{Case study: St Johannes church}

Since the vault of the main nave of St Johannes church has an extreme shape and is thin, it was not possible to find thrust networks with TNA that fitted within the geometry, or to find a complete solution using parametric thrust line analysis with the slicing method. The failure to find a TNA-based solution might be attributed to the available methods lacking a best fit solution, but the results indicate that the analysis made in this study, with TNA and parametric thrust line analysis, validates the findings from the earlier analysis that it is not possible to find thrust lines or thrust networks that fit completely within the geometry of the vaults.

The analysis of a section of the church by means of parametric thrust line analysis clearly showed the efficiency of the buttresses and the flying buttresses to counteract different types of loading from the vaults and the roof structure to ensure that the forces in the inner columns of the church are always located at their centre, see Figure 6. The results show the strength of the methods used to describe and study the global force pattern and the clever structure of the flying buttresses to support and allocate the thrusting forces from the vaults and roof structures.
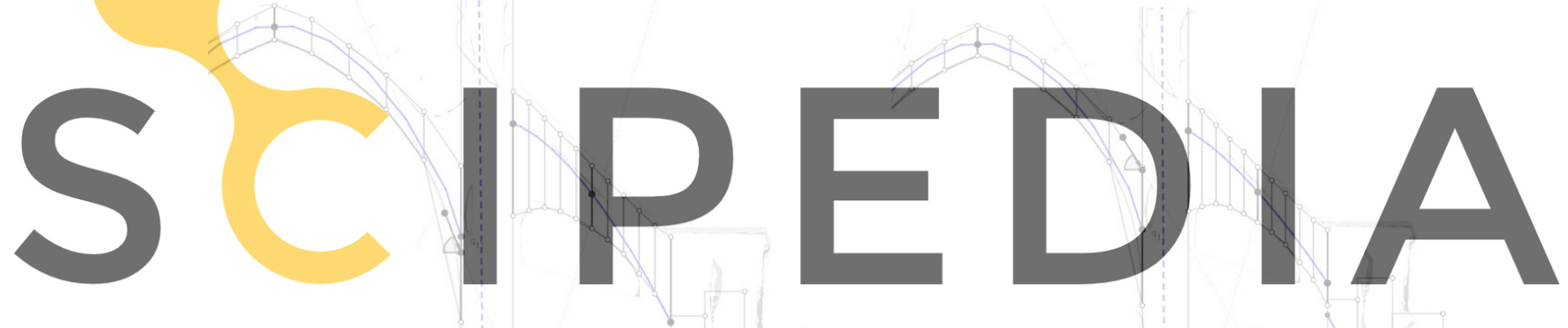

Register for free at https//www.scipedia.com to download the version without the watermark
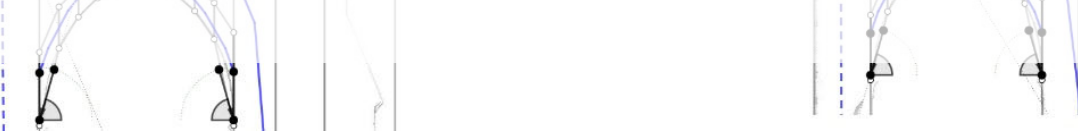

Figure 6: An example of the flexible response of the flying buttresses to different loads. The analysis to left shows the case without wind loading on the roof structure, and the analysis to the right shows the case with wind loading. The increased thrusting force from the central nave is counteracted by the flying buttresses.

\section{CONCLUSIONS}

The development of computer-based methods to capture complex geometries and to carry out modelling and analyses has created entirely new possibilities to study and assess complex masonry structures. By using the proposed approach to carry out funicular analysis of historic vaulted masonry structures, it is possible to perform analyses and assessments with a reasonable work effort and length of normal project and achieve results of the required quality for practising structural engineers. The methods are efficient for the analysis of complex structures. The methodology also provides a pedagogical description of the structural behaviour of masonry vaults and the decisive factors for their load-carrying capacity. $3 \mathrm{~d}$ models facilitate the perception and understanding of the analysis and results. 
Thrust Network Analysis (TNA) has the potential to become a very useful and efficient tool to analyse historic masonry vaults. For this, a solution to fit the thrust networks to existing geometries is needed. The availability of a best fit solution is also needed to find the most optimal and valid shapes within the geometry of the vaults, depending on the objective of the analysis. Thrust Network Analysis is faster than parametric thrust line analysis by means of the slicing method, and provides the possibility to examine rapidly many different ways that the vaults can carry loads, as well as different loading situations in a sensitivity analysis.

To carry out a thrust line-based analysis for vaulted structures, a target surface needs to be defined in some way. With a best fit-based solution in TNA, a target surface to which the thrust network can be optimised must be defined. The distance from the resulting thrust network and the target surface gives a measure of how well suited the given shape is to be a load-carrying structure for compression only. In analyses of historic masonry vaults, the analyst needs to know which shape is aimed at to describe the structural behaviour of the vaulted structure. The thrust network needs to be located within the geometry of the vaults but, in theory, there can be endless valid variations of its shape. The extremes are given by the flattest possible shape, with the network close to the intrados at the top of the vault and close to the extrados at the support of the vault, and the "deepest" possible shape, with the network close to the extrados at the top of the vault and close to the intrados at the support of the vault. The second case gives the least thrusting force and represents the vault "at rest" and not affected by other forces. Many times, it is desirable to show that the vault has a safe shape and that it is possible to fit a thrust network within the middle third of the geometry. The shape of the target surface therefore needs to be defined according to the questions at hand. The desired shape of a target surface is often far from obvious for vaults with complex shapes. The shape of different target surfaces needs further development and definitions for future studies.

The parametric thrust line analysis is a useful tool to study different load cases and to examine the load paths through the built structure to the foundations. A delimitation of possible structural solutions is obtained by combining thrust line analysis of sections of the buildings with analysis of the vaults' thrusting forces.

Acknowledgements. The Sven Tyrén trust at Tyréns AB has funded major part of the study presented in this paper. The church of Sweden with the cathedral council in Lund, the Parish of Gökhem and the Parish of St Johannes has provided us with the interesting case studies. The Block Research Group welcomed us to a valuable study visit.

\section{REFERENCES}

[1] Heyman, J. The Stone Skeleton: Structural Engineering of Masonry Structures. Cambridge University Press, England (1995).

[2] Huerta, S. The Analysis of Masonry Architecture: A Historical Approach. Architectural Science Review, Vol. 51.4: 297-328 (2008).

[3] Block, P. Thrust Network Analysis: Exploring Three-dimensional Equilibrium. Diss. Massachusetts Institute of Technology, Cambridge, MA, USA. (2009).

[4] Block, P., Ciblac, T. \& Ochsendorf J. A. Real-time limit analysis of vaulted masonry buildings. Computers and Structures 84 (29-30), 1841-1852. (2006).

[5] Thelin, C., Höst, F. \& Rosenberg, C. Att förstå verkningssätt och fånga geometrin i 
historiska murverkskonstruktioner, Bruk av ruiner, Balksten, K. \& Mebus U., eds. (2013), Visby: Fornsalens förlag. (2013).

[6] Historic England, 3D Laser Scanning for Heritage: Advice and Guidance on the Use of Laser Scanning in Archaeology and Architecture. Swindon. Historic England. (2018).

[7] Thelin, C., Höst, F. \& Rosenberg, C. Analysis of historic masonry structures supported by 3D laser scanning. Proceedings of the 8th International Conference on Structural Analysis of Historic Construction, Jasiénko, J. (red). SAHC-2012, 15-17 October 2012, Poland. (2012).

[8] O'Dwyer, D.W. Funicular analysis of masonry vaults. Computers and Structures 73 (15), 187-197 (1999).

[9] Block P., Lachauer L. \& Rippmann M. Thrust Network Analysis - Design of a cut-stone masonry vault, Shell Structures for Architecture: Form Finding and Optimization, Adriaenssens, S., Block, P., Veenendaal, D. and Williams, C. (editors), Routledge, London. (2014).

[10] Rippmann, M., Lachauer, P., \& Block, P. Interactive Vault Design. International Journal of Space Structures, Vol 27, No 4: 219-230. (2012).

[11] Rippmann, M. \& Block, P. Funicular Shell Design Exploration. Proceedings of the 33rd Annual Conference of the ACADIA, Waterloo/Buffalo/Nottingham, Canada. (2013).

[12] Rhinoceros. [Computer program]. http://www.rhino3d.com [2019-03-11]. (2019).

[13] 3DReshaper. [Computer program]. http://www.3dreshaper.com [2019-03-11]. (2019).

[14] Rippmann, M. Funicular Shell Design: Geometric Approaches to Form Finding and Fabrication of Discrete Funicular Structures. Diss. ETH Zürich, Schweiz. (2016).

[15] Block, P. \& Lachauer, L. Three-dimensional (3D) equilibrium analysis of gothic masonry vaults. International Journal of Architectural Heritage, Vol 8: 312-335. (2014).

[16] Block, P. \& Lachauer, L. Closest-Fit, Compression-Only Solutions for Free Form Shells, Proceedings of the IABSE-IASS Symposium 2011, London, UK. (2011).

[17] Panozzo D., Block P. \& Sorkine-Hornung O. Designing Unreinforced Masonry Models, ACM Transactions on Graphics - SIGGRAPH 2013,32(4): 91:1-91:12. (2013).

[18] Van Mele, T., Panozzo, D., Sorkine-Hornung, O. \& Block P. Best-fit thrust network analysis - Rationalization of freeform meshes, Shell Structures for Architecture: Form Finding and Optimization, Adriaenssens, S., Block, P., Veenendaal, D. and Williams, C. (editors), Routledge, London. (2014).

[19] Geogebra. [Computer program]. http://www.geogebra.org [2019-03-11]. (2019).

[20] Revit. [Computer program]. http://www.autodesk.com [2019-03-11]. (2019). 